\title{
Physics and application of plasma diagnostics, electrostatic confinement and characterization by optical emission spectroscopy
}

\author{
Física e aplicação de diagnóstico de plasmas,confinamento \\ eletrostático, e caracterização por espectroscopia de emissão óptica
}

Péricles Lopes Sant'Ana', Ana Catarina Freire², Michael Odstrcil2, Roger Jaspers²

\begin{abstract}
In this work, supplementary experiments were accomplished by using argon plasmas for studying in the field of nuclear fusion and plasma diagnostics. In this way, three attempts were accomplished to describe the physics of the probes, (plasma sheath), electrical breakdown and electro-static confinement assisted by Spectroscopy. (i) In the first attempt, Langmuir probes was aimed either to determine the electron density, temperature of the argon plasma, and the characteristic Current-Voltage curve (I-V). (ii) In the second attempt, the Paschen curve was acquired to demonstrate the effects that determine electrical breakdown in a gas, and then, it was possible determine the breakdown voltage. (iii) The last attempt, the electro-static confinement was analyzed using optical emission spectroscopy. The fusor has been suggested as a simple alternative to magnetic confinement. Although on fundamental grounds this claim cannot be supported, interesting physics aspects appeared, some of which have their counterpart in tokamak as well.
\end{abstract}

Keywords: Argon plasmas, Langmuir probes, Paschen curve, fusor, electro-static confinement, Optical Emission Spectroscopy.

\section{RESUMO}

Neste trabalho, experimentos complementares foram realizados usando plasmas de argônio para estudar no campo da energia nuclear, o diagnóstico de plasmas de fusão. Dessa forma, três experimentos foram realizados para descrever a física das sondas (na bainha do plasma), quebra dielétrica e confinamento eletrostático assistido por espectroscopia. (i) Na primeira tentativa, a sonda de Langmuir foi usada para se determinar a densidade de elétrons, a temperatura do plasma de argônio e a curva de corrente-tensão característica (I-V). (ii) Na segunda tentativa, a curva de Paschen foi adquirida para demonstrar os efeitos que determinam a quebra dielétrica em um gás e, em seguida, foi possível determinar a Voltagem em que ocorre a quebra dielétrica (iii) Na última tentativa, o confinamento eletrostático foi analisado usando espectroscopia de emissão óptica. A fusão foi sugerida como uma alternativa simples ao confinamento magnético. Embora, por razões fundamentais, esta afirmação pode não ser suportada, aspectos físicos interessantes apareceram, alguns dos quais têm contraparte em tokamaks.

Palavras-chave: Plasmas de argônio, sondas de Langmuir, curva de Paschen, fusão, confinamento eletrostático, espectroscopia de emissão óptica 


\section{INTRODUCTION}

\section{Langmuir probe}

An electrostatic probe was first used to measure the potential distribution in gas discharges on the ground by Joseph John Thomson. The theory was later developed by Irving Langmuir and his collaborators ${ }^{1}$. The technique, with further developments, has been extensively applied to the study of gas discharges. A Langmuir probe refers to an electrode immersed in charged particle plasma, whose current-voltage (I-V) characteristics can be measured. From the I-V characteristics, one can estimate the temperature and number density of thermal electrons as bulk parameters which a DC bias is applied. The ideal I-V curve is demonstrated in Fig. 1.

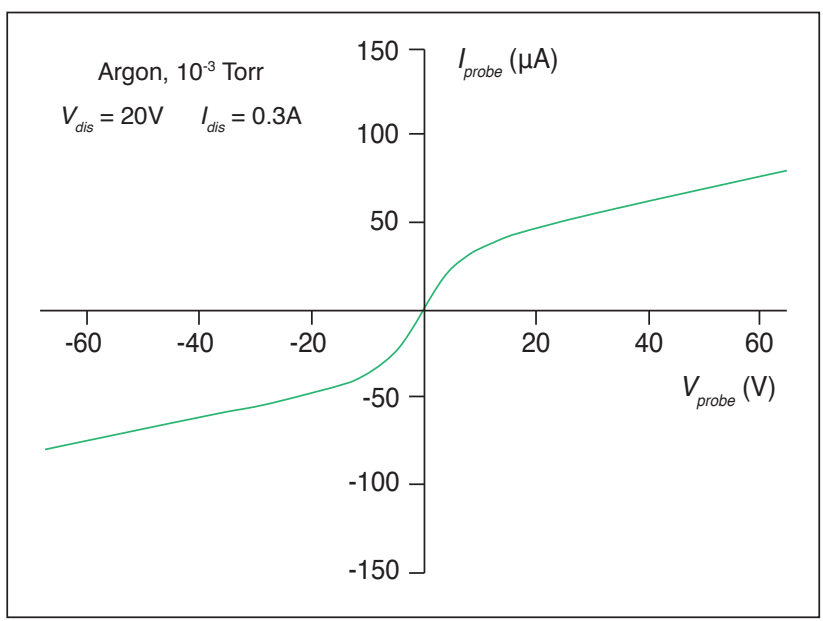

Figure 1: Typical double probe $\mathrm{I}-\mathrm{V}$ characteristics in a nearly Maxwellian plasma (low discharge voltage, high argon pressure) ${ }^{2}$.

In other studies, the effects of RF potential oscillation on the Langmuir probe characteristic I-V were described. This method is based on using a time-averaged Langmuir probe $\mathrm{I}-\mathrm{V}$ characteristics ${ }^{3}$. The $\mathrm{I}-\mathrm{V}$ characteristics has three different regions: 1) ion saturation region where the electrons are repelled but ions are collected; 2) electron retarding potential region where most of the current is due to electrons, but the actual current is determined by the number of electrons which can overcome a retarding potential; and 3) electron saturation region where ions are repelled but electrons are attracted to the probe. The probe leads were shielded by bare metal tubes to eliminate RF interferences in the probe circuits as has been done in previous research ${ }^{4}$.

When a probe is immersed in plasmas, its current generally depends on the collections of positive ions, negative ions, and electrons. We consider the electron current on a spherical probe under the condition that the electrons have a Maxwellian velocity distribution in a coordinate system fixed with respect to the probe. Recent studies report the use of tungsten filament (probe) for plasma diagnostics ${ }^{5}$. Other work ${ }^{6}$, also was dedicated to probe measurements in RF plasmas using bare metal protective shields underneath the floating potential.
For understanding, developing and maintaining plasma processes, it is desirable to determine the basic plasma parameters ${ }^{7}$, like electron temperature, plasma density and their dependence on the discharge voltage and operating gas pressure. Nowadays, it was reported in literature the use of Langmuir probe to measure these parameters ${ }^{8}$.

Electron plasma parameters such as density, temperature and the energy distribution depend on the plasma operating conditions such as gas composition, pressure, applied power, reactor geometry and reactor material ${ }^{9}$.

In recent studies, standard probe measurements were determined to registering the following parameters of plasma: electron temperature (Te), electron concentration (ne), floating potential of probe (Vf), potential of space (Vs), and its corresponding density of electron saturation current (jes). These parameters quite sufficiently characterize the physical state of plasma ${ }^{10}$. In addition, other studies considered the particle mass $\left(\mathrm{m}_{\mathrm{p}}\right)^{11}$ as an important parameter.

There are several factors which may prevent accurate measurement of electron temperature and density in plasmas by Langmuir probes. Among them, a contamination of the probe surface is one of the most potential sources of error. In particular, the electron temperature tends to be estimated to be higher than the true value when the probe has a contaminated surface. Hysteresis in the measurement of I-V characteristics may also be seen in such a situation ${ }^{12}$.

In general, the electron current is calculated by subtracting the ion current from the probe current, where the ion current is estimated by extrapolation from the ion saturation current. Electron current is completely controlled by the ion saturation current so that probe draws very little amount of current without disturbing the plasma conditions ${ }^{13,14}$.

The electron temperature is estimated from the gradient, which is proportional to $1 / \mathrm{Te}$, in a plot of $\log (\mathrm{Ie})$. The random electron current is a function of the electron temperature and density. Therefore, once the random electron current and the electron temperature are known, the number density of electrons can be calculated. In other recent studies, it was noted that parameters such as the electron density and the electron temperature can also be obtained from the electron energy probability function $(\mathrm{EEPF})^{15}$. More recent studies can be found in literature ${ }^{16-19}$.

An investigation into the referencing limitations of probe was presented by $\mathrm{Babu}^{20}$, however, it is rarely observed in argon plasmas. For another gas, recent studies reported its dielectric properties using Langmuir Probe ${ }^{21-24}$.

\section{Paschen curve}

The electric breakdown of gases is one of the fundamental phenomena of gas discharge physics. It has been studied for a long time but still attracts incessant interest of researchers ${ }^{25}$. Besides the interesting physics, breakdown is important for many applications including development of reliable electric insulation 
in electric grids and the study of different aspects of gas discharge physics ${ }^{26,27}$. Normally, a breakdown is represented by the so-called Paschen curve or the Paschen law ${ }^{28}$.

The electrical breakdown occurs in Townsend regime when the ions reaching the cathode have sufficient energy to generate secondary electrons ${ }^{29}$. The reflection of electrons from the plasma volume walls is important in gas discharge physics. For example, this effect may have profound influence on probe measurements ${ }^{30}$. The ion-assisted field emission takes over in this regime and lowers the breakdown voltage considerably ${ }^{31}$.

The breakdown voltage $\left(\mathrm{V}_{\mathrm{b}}\right)$ for a particular gas and electrode material depends on the product of the pressure and the distance between the electrodes, as expressed in Paschen law. This breakdown voltage curve represents a balance between the number of electrons lost by diffusion and drift in the interelectrode gap and the number of secondary electrons generated at the cathode ${ }^{32}$.

$\mathrm{V}_{\mathrm{b}}$ increases as pd increases on the right side of the Paschen curve and increases with respect to the lowest breakdown value on the left side of the Paschen curve. For most gases, $V_{b}$ is a single-valued function of pd. At high pressures, breakdown voltage follows Paschen law until the electric field reaches the critical value and, after that, breakdown curve falls below the pure Paschen curve ${ }^{33}$.

For the breakdown, failures from the Paschen law are observed in different regions ${ }^{34}$. First, departure appears at the righthand branch of the curve corresponding to high pressures. The deviation is also noticed at the left-hand branch related to the low pressures and finally near the minimum of the breakdown curve. For each region, the required value for the electric field has to be of the order of $10^{6} \mathrm{~V} . \mathrm{cm}^{-1}$ or more to induce a field emission effect from the cathode.

The critical issue in extending the standard (gaps of distance $\mathrm{d}=1 \mathrm{~cm}$, and pressures $\mathrm{p}=1$ Torr) low pressure discharges to dimensions of the order of millimeters is how to predict the conditions that could lead to a breakdown ${ }^{35}$. In this way, we prefer to regard the Paschen curve (law) as the dependence of the breakdown voltage on pd (the pressure-gap product) without implying any analytic dependences ${ }^{36}$. It was found that when the additional electron emission due to the high electric field is included, the breakdown voltage decreases very rapidly with decreasing pd (for smaller pd) of the Paschen minimum. However, in a number of papers, experimental Paschen curves obtained for both DC and rf discharges displayed a plateau to the minimum and these curves disagreed with those obtained at standard dimensions $\mathrm{s}^{37,38}$.

In other study, the higher pd values the scaling of electrical characteristics and light emission intensity with electrode separation was verified ${ }^{39}$. Figure 2 shows a typical Paschen curve for a given gas, where the breakdown voltage $\left(V_{b}\right)$ was fitted as function of pressure $\times$ distance $(\mathrm{pd})$.

Other authors also reported that Paschen law predicts the value of the breakdown voltage as a function of the product of

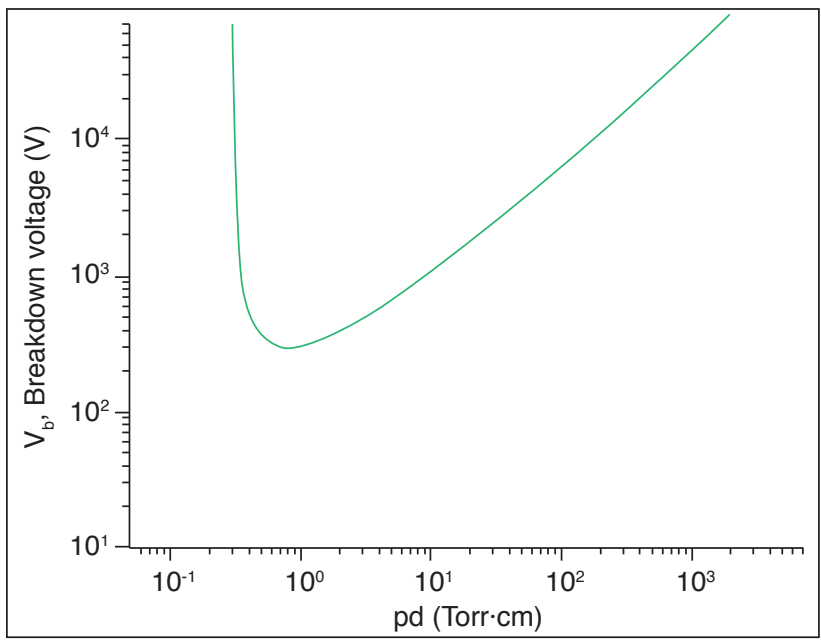

Figure 2: Typical Paschen curve. Breakdown voltage $\mathrm{V}_{b}$ (the voltage at which the plasma begins to arc) as function of pressure $\times$ gap distance $(\mathrm{pd})^{40}$.

the pressure and the interelectrode distance, $V_{b}=f(p d)$ in a given gas for a given reactor configuration ${ }^{41}$.

An additional and independent influence of the interelectrode distance on the breakdown voltage has been observed by Penning and Addink ${ }^{42}$, Miler ${ }^{43}$, Auday et al. ${ }^{44}$, Lisovskiy et al..$^{45}$, and Mariotti et al. ${ }^{46}$.

Moreover, breakdown voltage curves corresponding to the measured breakdown voltages for RF discharges in argon and DC discharges with various electrode materials can be found in another study ${ }^{47}$. Under the same discharge conditions (including capacitor voltage, cathode material, shape and electrode spacing), the electrode configuration with higher breakdown voltage is able to generate higher-density plasma since the cathode runaway electrons can gain relatively larger energy from the electric field ${ }^{48}$. In addition, the DC breakdown voltage curves in argon discharges for different gap spacing is described in literature ${ }^{49}$. Recent studies also revealed the voltage breakdown as function of product (pd) and Paschen curve using argon plasma for a distance $d=2 \mathrm{~cm}$, while the pressure was changed from 0.4 to $2.6 \mathrm{mbar}^{50}$.

\section{Fusor (electrostatic confinement)}

Atomic spectra are known to be a rich source of information about the structure of atomic nuclei without involving any model concepts. It was shown that spectroscopic methods may appear very promising for this kind of investigation ${ }^{51}$. Later, natural spectral-line broadening in atoms with unstable nuclei was explored by Gainutdinov ${ }^{52}$.

Spherical electrodes immersed into background plasma were first studied by Stenzel et al. ${ }^{53,54}$. In these two companion papers, the bias on the relevant electrode was positive with respect to ground. In this way, electrons can oscillate between the boundaries of the gridded anode. The main difference between the aforementioned works and this third experiment is that the sign for the electrode bias in this work is highly negative. Its amplitude is in fact so high 
that the ions can gain enough kinetic energy to undergo fusion reactions. Fig. 3 shows schematic of a possible experimental setup.

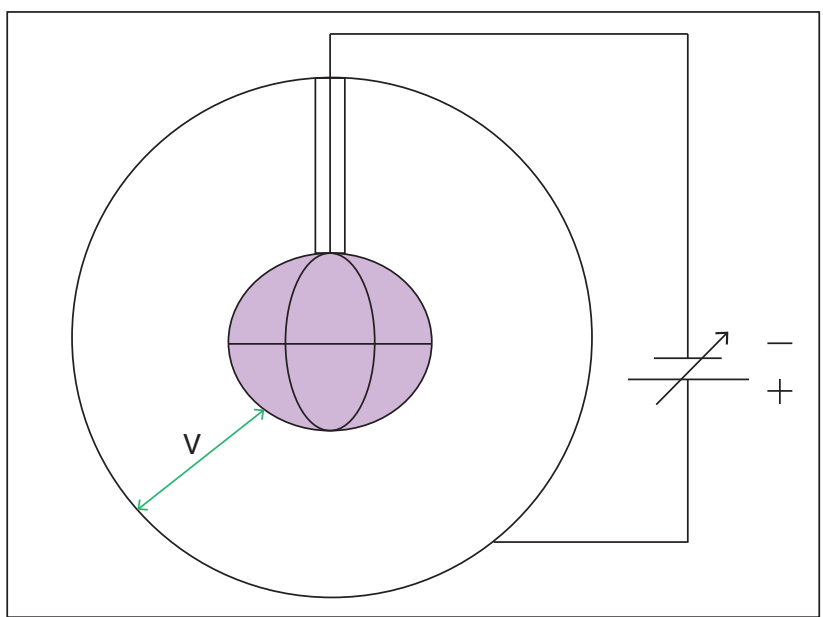

Figure 3: Schematic of a possible experimental setup. Ions are accelerated by the applied voltage into the grid in the center of the machine where they are able to fuse ${ }^{55}$.

Generally, spectral diagnostic methods attempt to establish relationships between the plasma parameters and the radiation features, such as the emission or absorption intensity and the broadening or shifting of the spectral lines ${ }^{56}$. An emission line is defined as the energy emitted per second and it depends on the probability of transitioning between the two involved energy levels and their electron population.

Several factors result in the broadening of the spectral lines. In the following, the most important factors for broadening are explained ${ }^{57}$.

The spectral lines are not infinitely sharp in wavelength or frequency, but has a spread in wavelength/frequency described by a Lorentzian profile. Hutchinson ${ }^{58}$ noted that spectral lines emitted by bound-bound transitions do not have an infinitesimal spectra width, but undergo several possible lines broadening mechanism useful for diagnostics.

Many studies in the literature on plasma parameters use the optical emission spectroscopy (OES) technique, which can be applied in many fields, from spatial plasmas $^{59}$ to laboratory experiments, such as in nuclear fusion ${ }^{60}$.

OES is the most popular technique to investigate glow discharges since it is simple and produces no perturbation in the plasma ${ }^{61}$. Some authors ${ }^{62}$ also have used OES for probing the cold plasma (few eV electrons), whose role is relevant in plasma stability. Nevertheless, OES is used to measure vibrational, rotational and gas temperatures ${ }^{63}$ and electron energy distribution functions $(\mathrm{EEDFs})^{64}$ in argon plasmas. Moreover, the optical emission spectrum of capacitive and inductive discharge has been compared in detail ${ }^{65}$. Fig. 4 shows the background line broadening for our experiments.

Recently, it was developed a nonequilibrium collisionalradiative model (CRM) for pure argon to calculate the populations of argon excited states and line intensities ${ }^{66}$. In particular, they focused on the light emission of the three most intense argon atomic lines at $811.5 \mathrm{~nm}, 763.5 \mathrm{~nm}$, and $750.4 \mathrm{~nm}$.

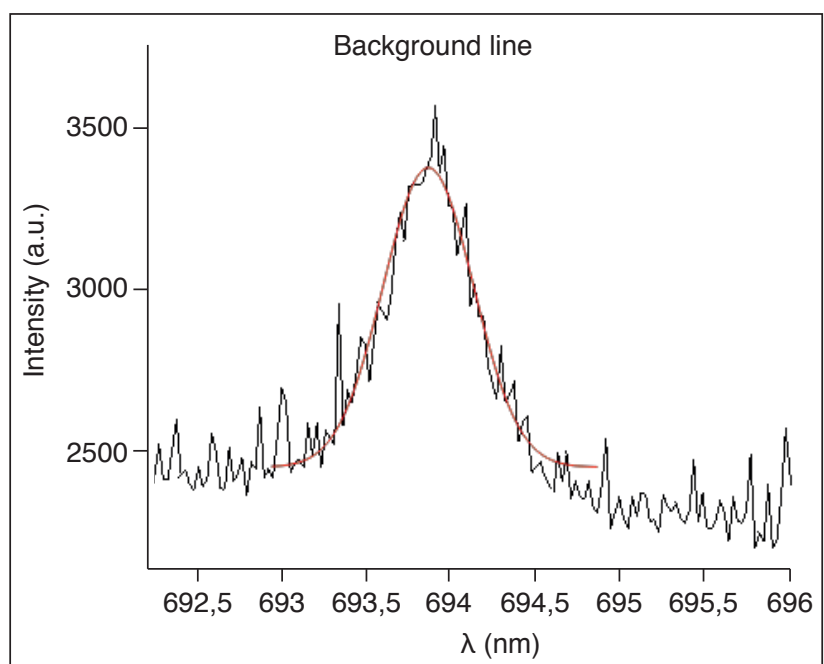

Figure 4: Background broadening acquired by optical emission spectroscopy (OES) for argon under $-10 \mathrm{kV}$ and $3.2 \times 10^{-3} \mathrm{mbar}$.

From OES measurements reported in the literature, it is known that the relative intensity of these dominant argon lines depends on the type of plasma. In capacitively coupled plasmas (CCP) ${ }^{67}$, inductively coupled plasmas (ICP) ${ }^{68}$, and glow discharges ${ }^{69}$, the $811.5 \mathrm{~nm}$ line is the dominant line in pure argon. For glow discharges $^{70}$, and CCP plasmas ${ }^{71,72}$, the relative increase in emission intensity is $811.5 \mathrm{~nm}>763.5 \mathrm{~nm}>750.4 \mathrm{~nm}$. In ICP plasmas $^{73,74}$, the intensity of $750.4 \mathrm{~nm}$ line is reported to be higher than the $763.5 \mathrm{~nm}$ line.

In pure argon, the $811.5 \mathrm{~nm}$ line presented the highest intensity because it originates from the $2 \mathrm{p} 9$ state, which is the most populated level. It is followed by the $763.5 \mathrm{~nm}$ line, which originates from the $2 \mathrm{p} 6$ level with the second highest population, and finally, by the $750.4 \mathrm{~nm}$ line, which originates from the least populated $2 \mathrm{p} 1$ state $^{75}$.

The electron impact excitation cross sections out of the argon ground state are taken from literature ${ }^{76}$. The electron impact excitation rates out of the argon ground state account for direct excitation only. The total rates, however, include cascades from higher lying levels.

Emitting atoms suffer frequent collisions with other atoms and ions in the plasma, which produces distortion of their energy levels. This is a mechanism leading to the so-called collisional broadening of the emission lines. Depending on the nature of disturbing particles, there are different types of collisional broadenings: Van der Waals, resonance and Stark broadenings.

The Van der Waals broadening is due to dipole moment induced by neutral atom perturbers in the instantaneous oscillating electric field of the excited emitter atom ${ }^{77}$. The resonance broadening of spectral lines is due to dipole-dipole interactions of the emitter with ground-state atoms of the same element ${ }^{78,79}$. 
The Stark broadening results from Coulomb interactions between the emitter atom and surrounding charged particles, perturbing the electric field it experiences. Both ions and electrons induce Stark broadening, but, in nonthermal plasmas, electrons are responsible for the major part of it because of their higher relative velocities ${ }^{80}$.

These three collisional broadenings mechanism generates a Lorentzian shape profile with a FWHM for argon.

\section{EXPERIMENTAL}

In the first attempt (i), an insulating probe with tungsten electrode tip was positioned in argon plasma. A voltage stepping between a lower and upper limit was applied between the probe tip and the plasma. The tips measured $1910^{-3}$ and $3 \times 10^{-3} \mathrm{~m}$. The area was $1.3273 \times 10^{-4} \mathrm{~m}$. The current running from the electrode to the plasma was recorded and the I-V was fitted to determine plasma temperature and density. The source $300 \mathrm{VDC}$ was applied to an alternative electrical configuration, the pressure in the chamber was $8.0 \times 10^{-5}$ bar. The series resistors reached $1.2 \times 10^{3} \Omega$ and the maximum current $\left(\mathrm{i}_{\max }\right)$ reached $100 \times 10^{-3} \mathrm{~A}$. The computer-controlled probe was calculated using a "Keithley 2400" source meter from Tektronix Company.

In this second attempt (ii), an argon plasma was used to record the breakdown voltage as a function of pressure and distance between the electrodes until the saturation of electrical current using a DC power supply. In the first step, the argon pressure was changed from $0.08 \times 10^{-3}$ to $47.4 \times 10^{-3} \mathrm{bar}$, while the distance between the electrodes was fixed to $3.6 \times 10^{-3} \mathrm{~m}$. The voltage applied was changed from $3.2 \times 10^{3}$ to $2.6 \times 10^{6} \mathrm{~V}$, while the output current was $4 \times 10^{-3} \mathrm{~A}$. The objective was to fit the curve voltage $\times$ pressure. In the second step, the pressure was fixed at $1 \times 10^{-3}$ bar and current $4 \times 10^{-3} \mathrm{~A}$, while voltage was changed from 260 to $500 \mathrm{~V}$, in order to collect the voltage $\times$ distance curve. Figure 5 shows the scheme of experimental plasma system for i and ii.

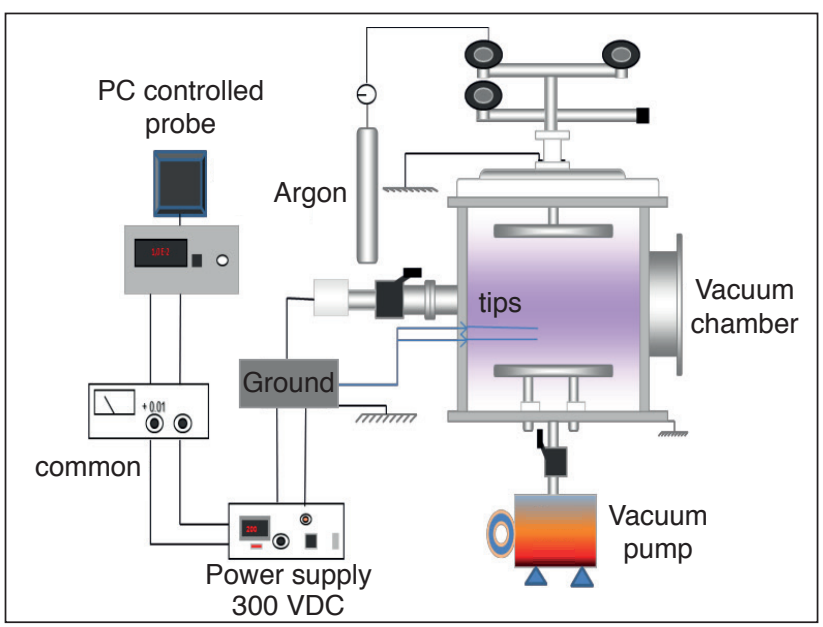

Figure 5: Scheme of experimental plasma system for $\mathrm{i}$ and ii. The diameters of the tips are: $\varnothing=3 \mathrm{~mm}$ and $\varnothing=19 \mathrm{~mm}$. The PCcontrolled probe was a "Keithley 2400".
In the third attempt (iii), another plasma system was used for the electrostatic confinement, which was accomplished in a selfbuild fusor experiment consisted in a spherical vacuum chamber with diameter of $50 \times 10^{-2} \mathrm{~m}$, containing an internal grid at $100 \times 10^{3} \mathrm{~V}$ potential in a low electrical current of $\sim 15 \times 10^{-3} \mathrm{~A}$, using argon plasmas in a pressure work of $3.2 \times 10^{-6}$ bar. The measurements of plasma parameters were acquired using OES and density profile was determined. It was possible to fit the four spectral lines of optical emission from temperatures between 7 to $10 \mathrm{eV}$.

The underlying concept is rather simple: a high voltage of several $\mathrm{kV}$ (up to several hundred $\mathrm{kV}$ ) accelerates ions from background plasma radially into the inner grid electrode where they collide and fuse. The frequently used working gases are a mixture of deuterium and tritium or pure deuterium gas, which is not, was available.

The scheme of experimental plasma fusor system for iii can be observed in Fig. 6.

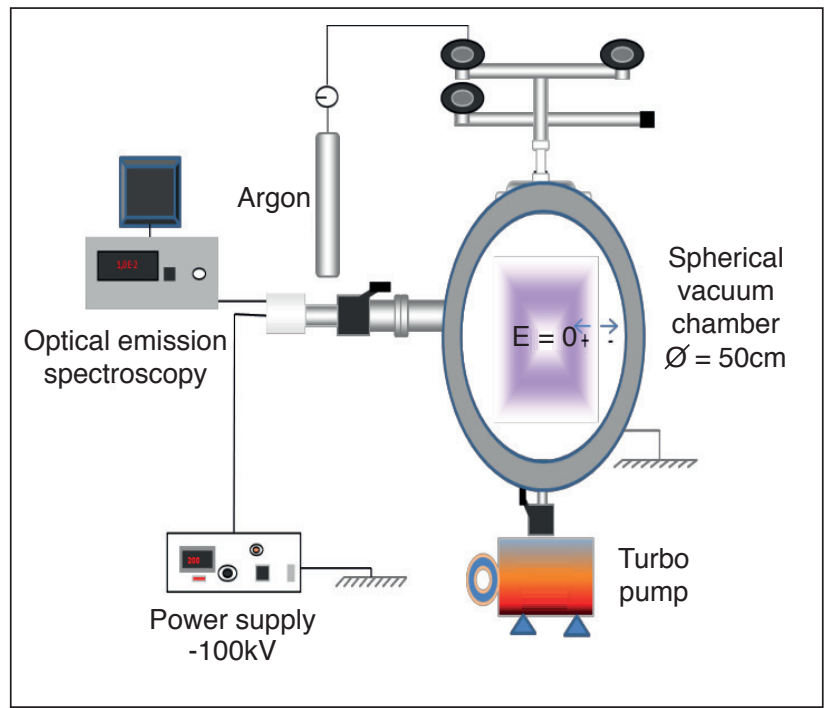

Figure 6: scheme of experimental plasma fusor system for iii. Argon ions are accelerated by the applied negative voltage of $-100 \mathrm{kV}$ into the grid in the center of the reactor.

The argon gas was used as an alternative for the iii experiment. For this experiment, it is assumed that the system does not present a perfect spherical symmetry; it is possible to obtain grid loss energy collision losses, and finally, at center, the electric field $(\mathrm{E} \neq 0)$.

\section{RESULTS AND DISCUSSIONS}

Langmuir probe and optical spectroscopy were recently studied $^{81}$ using argon plasma ${ }^{82}$. Argon gas is considered as one of the most often used gases in plasma technologies. The relative cheapness of argon also enables it to be used as the carrier gas in industry ${ }^{83}$. The results and discussions are presented for the three experiments (i, ii and iii): 


\section{Experiment $\mathbf{i}$}

The electron density and temperature are the basic parameters that characterize space plasmas; they were obtained through in situ measurements by using Langmuir probes, which is in agreement with recent studies ${ }^{84}$. The $\mathrm{I}-\mathrm{V}$ characteristic can describe the operating regime of the electric discharge. Using this I-V curve, the plasma parameters of interest can be calculated ${ }^{85}$. To obtain the I-V characteristic, the power supply voltage was varied for a top current of $2.8 \times 10^{-6} \mathrm{~A}$, in an area of $1.3273 \times 10^{-4} \mathrm{~m}$, while the argon pressure was $1.338 \times 10^{-3}$ bar.

The real current saturation cannot be estimated for this range. Thus, the curve represents the transition region between electronic and ionic current saturation. In this region, while the electric field is very small, the value of the current (some tens of $\mu \mathrm{A}$ ) will be proportional to the rate at which the ions and electrons move toward the electrodes. Under these conditions, the density of current is proportional to the electric field and the voltage range, reaches some tens of volts, and independently of how potent is the power source. Fig. 7 shows the results obtained in this study.

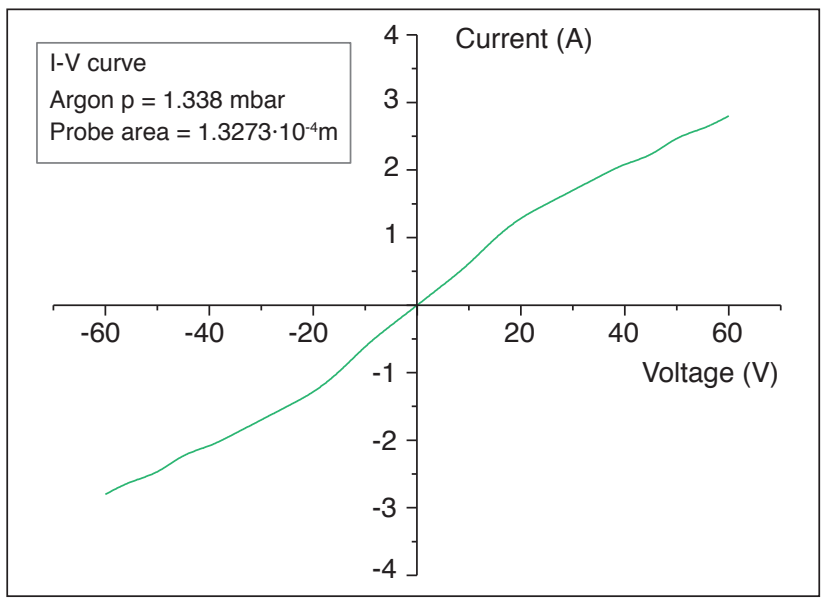

Figure 7: I-V curve resulted from i experiment.

At $1.338 \times 10^{-3}$ bar $(\sim 130 \mathrm{~Pa})$, the random flux $(\Gamma)$ of argon atoms (a.m.u 40) at room temperature is $2 \times 10^{25}$ atoms $\mathrm{m}^{-2} \cdot \mathrm{s}^{-1}$. The distance travelled by an argon atom between collisions will be on average about $0.11 \times 10^{-3} \mathrm{~m}$, and the frequency of collisions between gas atoms at room temperature is $3.5 \times 10^{6} \mathrm{~s}^{-186}$. The linearity observed on the graph is interpreted as follows: as long as the electric field is very small, the equilibrium between the production and the loss of charge in the medium will be maintained and the current value will be proportional to the speed with which the ions and electrons move towards the electrodes. Under these conditions the current density is proportional to the electric field and, consequently, the phase is an ohmic conductor.

On the other hand, the ranges of data collection from current and voltage were not sufficient to fit the curve as the I-V curve described in Figure 1, thus the fitted curve is quite linear in this range for those plasma conditions. It is suggested that the probe currents in this experiment were saturated at the maximum voltages of 60 and $-60 \mathrm{~V}$. Thus, the plasma potential should be smaller than $60 \mathrm{~V}$ because the electrons moved from the plasma to the probes by the electric force of the applied saturation voltage.

Extrapolating this region, the plasma discharge will be in progress, thus, when the bias voltage on the probe reaches a sufficiently negative value with respect to the plasma potential, the probe collects the ion saturation current. Positive ions continue to be collected by the probe until the bias voltage reaches the plasma potential; at this point, ions begin to be repelled by the probe. If the bias voltage is higher than the plasma potential, all positive ions are repelled, and the ion current to the probe vanishes ${ }^{87}$. Similarly, when the probe is positively biased, then most of the current to the probe is due to electrons, but the actual current is determined by the number of electrons overcoming a retarding potential ${ }^{88}$.

Other works review probes in flowing plasma conditions at moderate to high pressures ${ }^{89,90}$. At higher pressures $(p>50 \mathrm{~Pa})$, the frequency of electron collisions with the plasma species also increases and the mean free path between successive collisions decreases. It shows that the electrons lose their energy in the discharge. Thus, as the chamber pressure increases, more and more energy is transferred from the electrons to the plasma species.

In addition, the elastic collisions of electrons with the plasma species can also play a significant role in reduction of ionization events. Similarly, at higher pressures, the high-energy tail depletes to low energies; as a result, the availability of highly energetic electrons for electron impact ionization processes and, consequently, the electron number density $\left(\mathrm{n}_{\mathrm{e}}\right)$ decreases. This depletion in the tail of the electron energy distribution function might be due to rapid diffusion and recombination of highly energetic electrons at the chamber walls ${ }^{91,92}$.

At low pressure, when mean free paths are relatively long, the electrons remain much hotter than the gas; conversely, at high pressures, thermal equilibrium can be approached. A crude estimate of the electric field in a self-sustaining plasma can be obtained by supposing that electrons travel their entire free path in the direction of the field and lose all the energy gained in an optimum collision with the (cold) gas, (which suggests a scaling of temperature with $\mathrm{E} / \mathrm{p}$ ). This gives several volts $/ \mathrm{cm}$ at next to 1 Torr in argon $(133.32 \mathrm{~Pa})$.

\section{Experiment ii}

If an electric field is applied to a plain parallel gap of width (d), containing a gas, at sufficiently high fields, the gas suddenly switches from being insulating dielectric to conducting gas. It is supposed that a few electrons are always around in the gap, either by the action of cosmic rays or else as a consequence of field emission from asperities on the surface, close to which electric fields are strongly enhanced. Our results are consistent with the theory ${ }^{93,94}$ that predicts the violation of scaling when field emission becomes significant only at gaps smaller than $10 \mu \mathrm{m}$. 
Our plasma reactor is designed in a DC configuration, and has two electrodes "cathode and anode", with an adjustable interelectrodes distance; the maximal interelectrodes spacing is approximately calculated. Fig. 8 shows the results of voltages as function of pressure, and voltage as function of electrode distance.

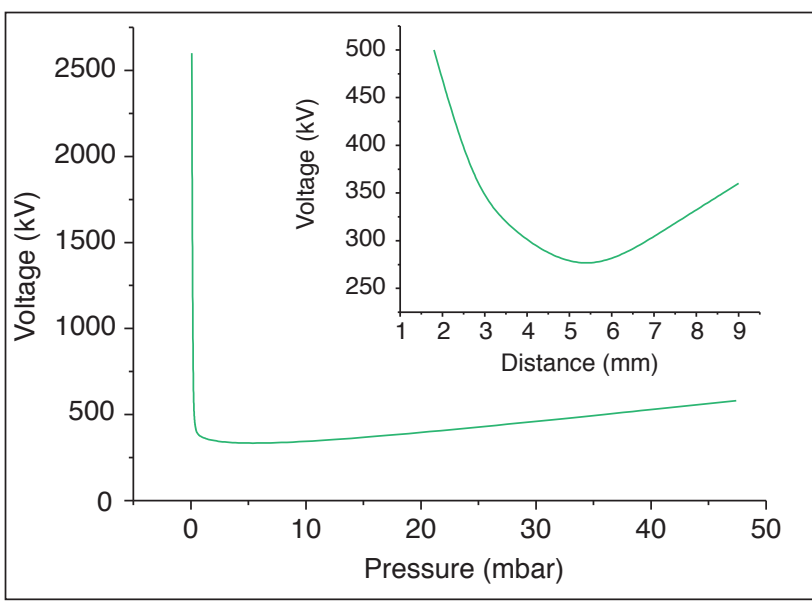

Figure 8: Graph of voltage applied (kV) as function of argon pressure (mbar) spectral emission lines resulted from experiment ii, enclousured to the graph of voltage $(\mathrm{kV})$ as function of electrode distance $(\mathrm{mm})$.

]The gap between the electrodes, so the electrons cannot gain enough energy to perform ionizations. Consequently, a higher voltage is required to assure ionization of enough argon gas atoms to start an avalanche. Argon is monoatomic and tends to have smaller diameters and, therefore, a greater mean free path length. Figure 9 shows the Paschen curve as result of the experiment ii $^{95}$.

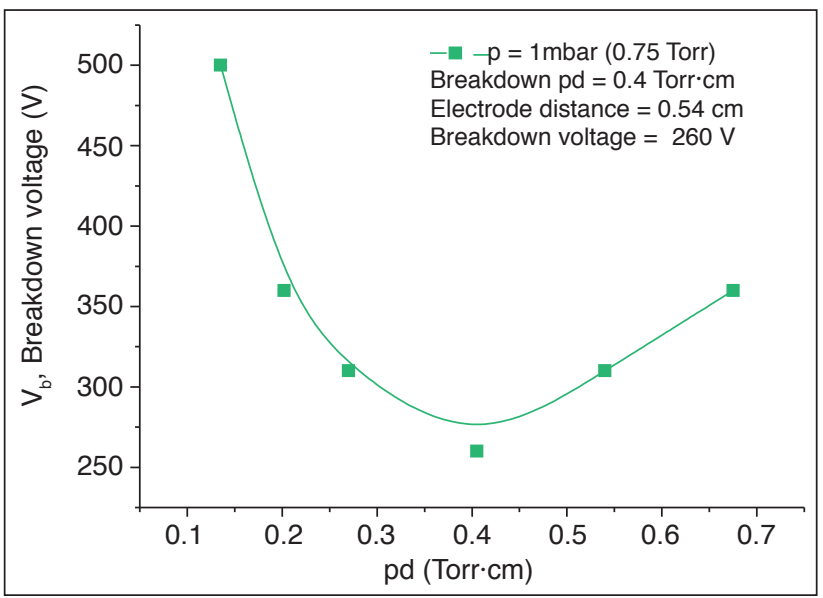

Figure 9: Graph of $\mathrm{Vb}$, breakdown voltage (V) as function of argon pressure (Torr) $\times$ electrode distance $(\mathrm{cm})$, which represents the Paschen curve for experiment ii.

The shape of the curve can be attributed to the increase of collision on the left side and decrease of ionization cross section on the right side ${ }^{96}$.

To determine the breakdown threshold, the electric field distortion can be neglected, and the field can be assumed uniform and equal to the applied field ${ }^{97}$. As with DC (and low-frequency) breakdown, higher values of pd require larger voltages to achieve breakdown, and at low pd there is again a sharp rise in breakdown voltage. For a pressure of 1 mbar (0.75 Torr), the minimum breakdown voltage $(\mathrm{Vb})$ is $260 \mathrm{~V}$.

If the long path explanation is considered then, the penetration of the discharge into the gap between the electrode and the insulator allows the discharge length to vary as required and the breakdown voltage stays close to the minimum value ${ }^{98}$.

\section{Experiment iii}

The total collisional broadening result from the convolution of sum of the three mechanisms (Van der Waals, Resonance and Spark broadening).

The Lorentzian line shape typical of natural broadening: $\mathrm{I}(\mathrm{v})=\left(1+\Delta \mathrm{v}^{2}\right)^{-1}$, with $\Delta \mathrm{v}$ in units of $1 / 2 \Pi \mathrm{t}$, where $\mathrm{t}$ is the lifetime of argon atom in an upper state. This arises straightforwardly from the Doppler shift caused by thermal argon particle motion. The thermal Doppler broadening is one of the explanations for the broadening of spectral lines. Figure 8 shows the spectral emission lines from $4 \times 10^{-3}$ mbar of argon plasma under $-10.0 \mathrm{kV}$ and $15 \mathrm{~mA}$. In addition, the energies for fusor are 17.6 and $91.1 \mathrm{MeV}$. Fig.10 shows the image of the spectral emission lines from argon plasma.

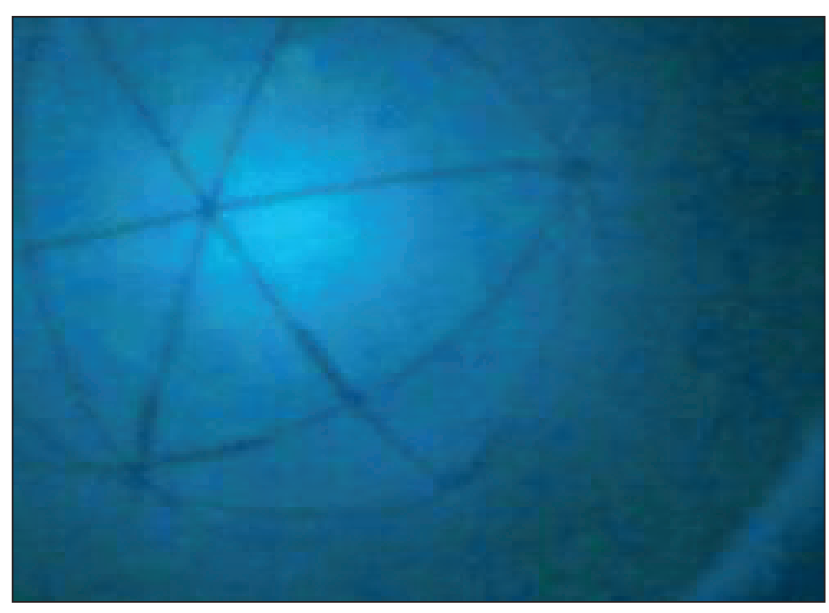

Figure 10: Photography of argon spectral emission lines resulted from experiment iii by applying of $-10 \mathrm{kV}, \mathrm{I}=20.2 \mathrm{~mA}$ and $4 \times 10^{-3} \mathrm{mbar}$.

Different velocities of the argon particles emission result in different Doppler shifts, the cumulative effect of which is the line broadening ${ }^{99}$.

Table 1 shows the values of retrieved parameters acquired by OES.

In general, the production processes of excited species include the electron-impact excitations from the ground and from the metastable states, the radiation decay from the higher excited states, etc. The following calculations are based on the assumption that the plasma between the two spherical electrodes is collisionless (this is reasonable because most of such electrostatic confinement fusion experiments are carried out at a pressure 
around $10^{-6}$ bar, where the mean free paths are in the order of the size of the machine).

The spectral lines emitted by bound-bound transitions do not have infinitesimal spectral width, but undergo several possible line broadening mechanisms that are extremely useful for diagnostics. The energy spread arises because perturbations of the atomic system due to interaction with the electromagnetic fields of virtual (or real) photons cause the quantum states to be only approximate eigenmodes of the system. The temperature was measured for different potentials. For each applied potential, the wavelength resulted to the same peaks formation, around $420 \pm 0.5$ and $528 \pm 0.5 \mathrm{~nm}$.
Figure 11 shows the broadening lines for argon temperatures from 7 to $10 \mathrm{keV}$. The spectrum of intensity lines is showed as function of wavelength ( $\mathrm{nm})$.

The moderated fields act not to split the upper emitting state, but it rather acts to broaden the emitted line. It was shown earlier that this effect leads to inhomogeneous broadening of spectral line, i.e., the emitted line becomes of Lorentzian shape on contrast to other broadening mechanisms, e.g. Doppler effect, which leads to a homogeneous broadening ${ }^{100}$.

In recent literature, a method to circumvent this dependence on electron density by considering pairs of emitted lines was proposed. This method allows the determination of the gas

Table 1: Values of data acquired by optical emission spectroscopy from argon plasma with $E=-10 \mathrm{keV}, \mathrm{I}=20.2 \mathrm{~mA}$ and $p=4 \times 10^{-3} \mathrm{mbar}$.

\begin{tabular}{|c|c|c|c|c|}
\hline Lines/energies & Area & Center & Width & Offset \\
\hline Cosmic line & -84958 & 648.34 & 323.06 & 856.11 \\
\hline Line 696 (Background) & -32750 & 691.72 & 19.72 & 3772.9 \\
\hline$T=7 \mathrm{keV}$ & $-1.737 \mathrm{E}-6$ & 528.5 & 325.61 & 5905.2 \\
\hline $\mathrm{T}=8 \mathrm{keV}$ & $-1.7375 \mathrm{E}-6$ & 528.5 & 325.6 & 5805.2 \\
\hline $\mathrm{T}=9 \mathrm{keV}$ & $-1.704 \mathrm{E}-6$ & 527.85 & 319.7 & 5895.7 \\
\hline$T=10 \mathrm{keV}$ & $-1.06 \mathrm{E}-6$ & 528.97 & 313.107 & 4356.0 \\
\hline
\end{tabular}
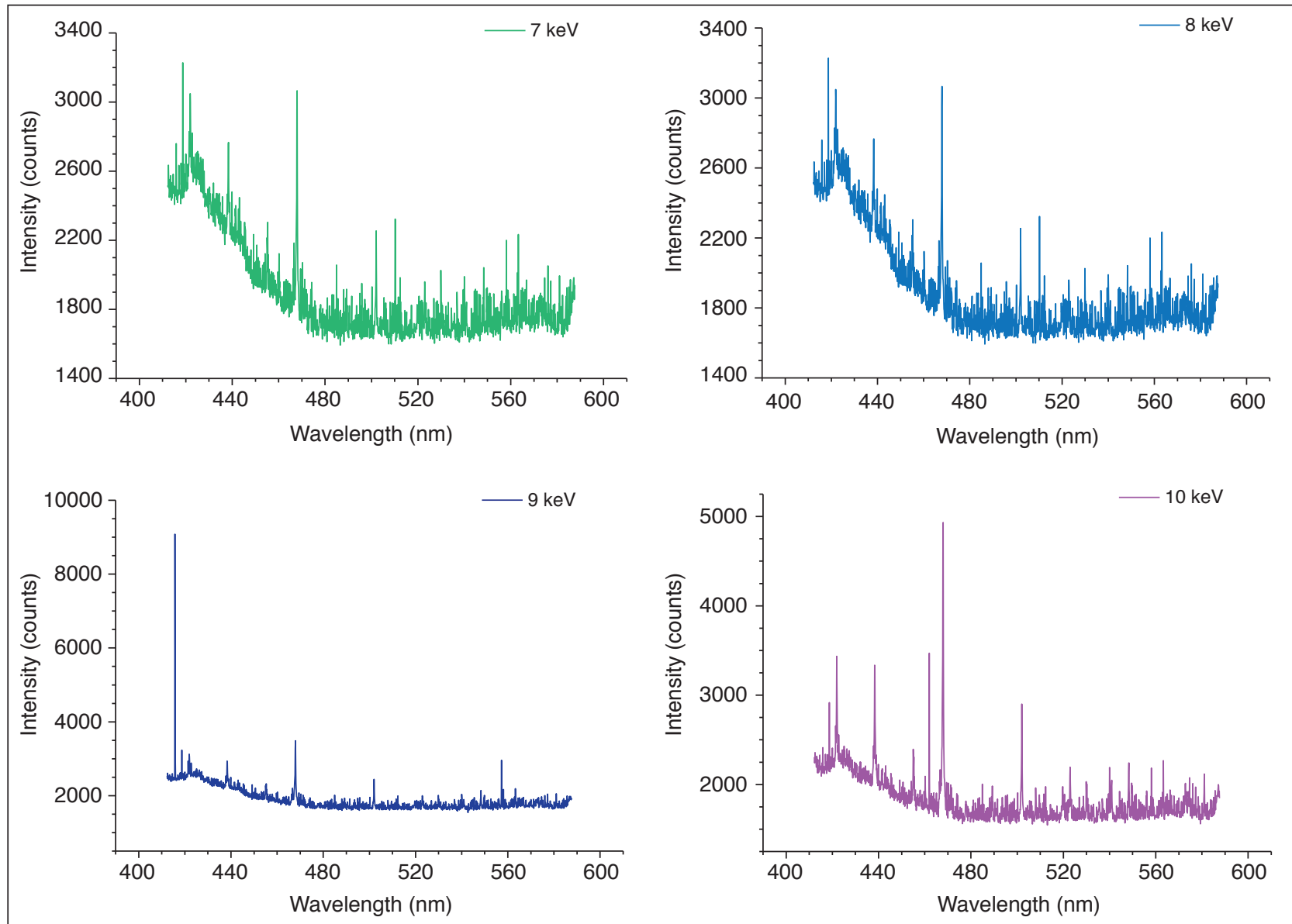

Figure 11: Spectrum of lines broadening from argon plasma resulted from experiment iii by applying $-100 \mathrm{kV}$ and $3.2 \times 10^{-3} \mathrm{mbar}$, in different temperatures. 
temperature from the measurements of Lorentzian profiles of some pairs of argon atomic lines, and when applying it, no assumptions on the degree of thermodynamic equilibrium among excited states are needed ${ }^{101}$.

For thermal plasmas with a gas temperature similar to the electron one, the mobility of ions is high and the impact approximation is also valid for ions, being their contribution to the broadening also being Lorentzian. In the ion impact limit, line profiles are symmetric Lorentzian. On the contrary, for plasmas where the ion mobility is small (e.g., plasmas with gas temperature relatively low), a quasistatic approximation is often needed to model the ion broadening in order to explain the slightly asymmetric shape of the profiles. The less dynamical the ions are, the more asymmetric the lines are.

Finally, Fig. 12 shows the spectrum of lines emission from argon plasmas resulted from experiment iii by applying of $-10 \mathrm{kV}$ and $3.2 \times 10^{-3} \mathrm{mbar}$ for different temperatures.

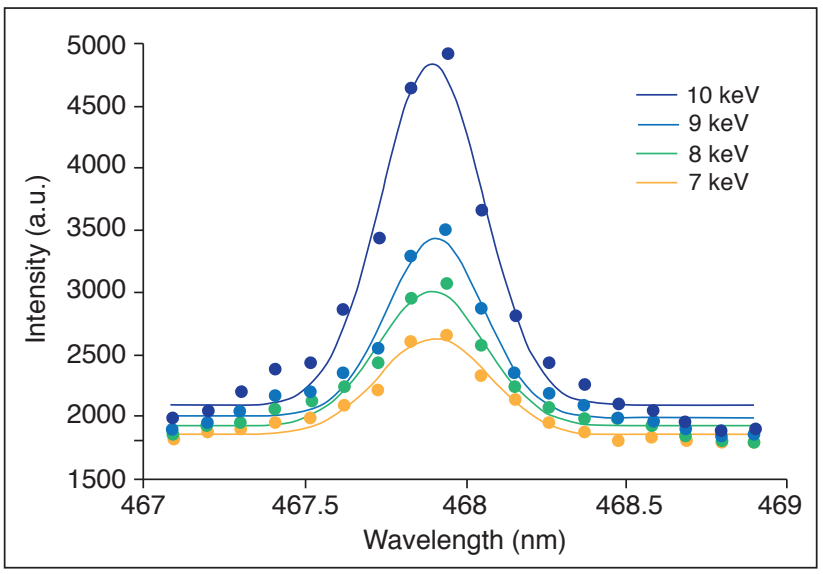

Figure 12: Lorentzian Spectrum of argon plasma resulted from iii experiment by applying of $-10 \mathrm{kV}$ and $3.2 \times 10^{-3} \mathrm{mbar}$.

The 4 peaks ranged between 467 and $469 \mathrm{~nm}$. The peaks of line broadening to argon comprise ions excitation (electronic transitions). While the fusor is in progress, the spectra intensity (counts) will change, and then it is possible to determine the temperature $(\Delta \mathrm{T})$ in the plasma. The data were collected applying high voltage of $-10 \mathrm{keV}$ while top current was $20.2 \mathrm{~mA}$.

The intensity of these lines is obtained from the spectrum by taking integration over the respective profiles and normalizing the same with the spectral response of the instrumental sensitivity.

The spectra emitted from plasma contain a wealth of information that are stored in the emitted line shape as well as the continuum radiation often appeared under the emitted lines. The relative spectral radiance (in the units of counts per second) of some emitted lines can be related to the plasma temperature, while the Lorentzian full width of the line at half of the maximum spectral radiance (FWHM) usually contains information about electron and/or ion density ${ }^{102-104}$.

The described discharge operation of argon is found in literature ${ }^{105}$. They developed the volume averaged global model for low-pressure high-density discharges for noble gases, including argon. While argon ions are moving a Maxwell-Boltzmann distance $\left(\Delta \mathrm{d}=\mathrm{d}-\mathrm{d}_{0}\right)$, there are photon emission with initial velocity $\left(\mathrm{v}_{0}\right)$ to final velocity $\left(\mathrm{v}_{\mathrm{f}}\right)$ due to energy loss.

Analyzing the FWHM, it can be estimated for each temperature with the equation $\Delta \mathrm{d}=\lambda_{2}-\lambda_{1} \approx 0.20 \pm 0.1 \mathrm{~nm}$. Using the equations $\mathrm{d} / \mathrm{d}_{0}=(1-\mathrm{v} / \mathrm{c})$, and $\Delta \mathrm{f}=\mathrm{v} / \mathrm{d}_{0}$, then, the estimated electrons frequency is $2.1363 \mathrm{MHz}$. The distance $\Delta \mathrm{d}$ does not change significantly for each condition, which means that the temperature does not change significantly as function of the applied $\Delta \mathrm{V}$.

\section{Measuring the temperature (Te) of thermal electrons and number density (ne) of thermal electrons in the argon plasma}

Input:

$\mathrm{m}$ argon $=40 \times 1.2710^{-27}=6.4 \times 10^{-26} \mathrm{~kg}$.

$\mathrm{c}=3 \times 10^{8} \mathrm{~m} / \mathrm{s}^{-1}$ (light velocity in vacuum)

$\lambda$ argon $=467.9 \times 10^{-9} \mathrm{~m}$ (spectral line position peak)

For $\mathrm{E}_{1}=17.6 \mathrm{MeV}$ (typical fusor energy):

$1 \mathrm{eV}=1.6 \times 10^{-19} \mathrm{~J}$

$17.6 \times 10^{6} \mathrm{eV}=\mathrm{x}$ J; then $\mathrm{x}=2.816 \times 10^{-12} \mathrm{~J}$

Velocity:

$\mathrm{V}_{01}=\left[\left(2.816 \times 10^{-12} \mathrm{~J} \times 467.9 \times 10^{-9} \mathrm{~m}\right) / 6.64 \times 10^{-34} \mathrm{~J} \mathrm{~s}\right]^{1 / 2}$

$\mathrm{V}_{01}=3.92 \times 10^{7} \mathrm{~m} \cdot \mathrm{s}^{-1}$.

For $\mathrm{E}_{2}=911 \mathrm{MeV}$ (fusor energy):

neutronicity $=0.8$

and power density $=34 \mathrm{~W} / \mathrm{m}^{3} / \mathrm{kPa}^{2}$

$1 \mathrm{eV}=1.6 \times 10^{-19} \mathrm{~J}$

$911 \times 10^{6} \mathrm{eV}=\mathrm{x} \mathrm{J}$; then $\mathrm{x}=1.457 \times 10^{-10} \mathrm{~J}$

Velocity:

$\mathrm{V}_{02}=\left[\left(1.457 \times 10^{-10} \mathrm{~J} \times 467.9 \times 10^{-9} \mathrm{~m}\right) / 6.64 \times 10^{-34} \mathrm{~J} \mathrm{~s}\right]^{1 / 2}$

$\mathrm{V}_{02}=1.01 \times 10^{8} \mathrm{~m} \cdot \mathrm{s}^{-1}$.

Using the equation 6.4 .8 p. $265,{ }^{106}$. The results showed that:

$\mathrm{E} / \mathrm{h}=\Delta \mathrm{v}_{1 / 2}=2 \mathrm{v}_{\mathrm{o}}\left(\mathrm{v}_{\mathrm{ta}} / \mathrm{c}\right)(2 \text { In } 2)^{1 / 2} ; \mathrm{v}_{\mathrm{ta}}^{2}=\mathrm{T}_{\text {argon }} / \mathrm{m}_{\text {argon }}$

Where: $\Delta \mathrm{v}_{1 / 2}$ is the full-width at half-maximum of the Lorentzian:

For $\mathrm{E}_{1}=17.6 \mathrm{MeV}$ :

$17.6 \times 10^{6} \mathrm{eV} / 6.64 \times 10^{-34} \mathrm{~J} \mathrm{~s}=2 \mathrm{v}_{01}^{2}\left[\left(\mathrm{~T}_{1} / \mathrm{m}\right)^{1 / 2} \times 1 / \mathrm{c}\right](2 \ln 2)^{1 / 2}$

$2.65 \times 10^{40} \mathrm{eV} / \mathrm{J} \mathrm{kg} \mathrm{s}^{-1}=4.63 \times 10^{15} \mathrm{~m} . / \mathrm{s}^{-1}\left[\left(\mathrm{~T}_{1} / \mathrm{m}\right)^{1 / 2} \times 1 / 3 \times 10^{8} \mathrm{~m} . / \mathrm{s}^{-1}\right]$

$1.71 \times 10^{33}=\left(\mathrm{T}_{1} / \mathrm{m}\right)^{1 / 2}$

$4.14 \times 10^{16}=\mathrm{T}_{1} / \mathrm{m}$

$\mathrm{T}_{1}=4.14 \times 10^{16} \mathrm{eV} / \mathrm{kg} \times 6.4 \times 10^{-26} \mathrm{~kg}=2.65 \times 10^{-9} \mathrm{eV}$ 


$$
\begin{aligned}
& \mathrm{T}_{1}=2.65 \times 10^{-9} \mathrm{eV} \times 17.6 \times 10^{6} \mathrm{eV}=0.046675 \mathrm{eV}^{2} \\
& \mathbf{T}_{1} \mathbf{e}=\mathbf{0 . 2 1} \mathrm{eV}=\mathbf{2 5 0 7 . 4 1} \text { kelvin }=\Delta \lambda \text { Gaussian }=\mathrm{d}-\mathrm{d}_{0} \\
& \text { Where: } \mathrm{E}(\mathrm{v})=\mathrm{A} \exp \left[-0.5 \mathrm{mv}^{2} / \mathrm{T}\right] \\
& \text { For } \mathrm{E}_{2}=911 \mathrm{MeV} \text { : } \\
& 911 \times 10^{6} \mathrm{eV} / 6.64 \times 10^{-34} \mathrm{~J} \mathrm{~s}=2 \mathrm{v}_{02}^{2}\left[\left(\mathrm{~T}_{2} / \mathrm{m}\right)^{1 / 2} \times 1 / \mathrm{c}\right](2 \ln 2)^{1 / 2} \\
& 1.37 \times 10^{42} \mathrm{eV} / \mathrm{J} \mathrm{s} \mathrm{kg} \mathrm{s}^{-1}=2.38 \times 10^{17} \mathrm{~m} / \mathrm{s}\left[\left(\mathrm{T}_{2} / \mathrm{m}\right)^{1 / 2} \times 1 / 3 \times 10^{8} \mathrm{~m} \cdot \mathrm{s}^{-1}\right] \\
& 1.73 \times 10^{33}=\left(\mathrm{T}_{2} / \mathrm{m}\right)^{1 / 2} \\
& 4.15 \times 10^{16}=\mathrm{T}_{2} / \mathrm{m} \\
& \mathrm{T}_{2}=4.15 \times 10^{16} \mathrm{eV} / \mathrm{kg} \times 6.4 \times 10^{-26} \mathrm{~kg}=2.66 \times 10^{-9} \mathrm{eV} \\
& \mathrm{T}_{2}=2.66 \times 10^{-9} \times 911 \times 10^{6} \mathrm{eV}=2.4228 \mathrm{eV}^{2} \\
& \mathrm{~T}_{2} \mathbf{e}=1.55 \mathrm{eV}=18065.41 \text { kelvin }=\Delta \lambda \text { Gaussian }=\mathrm{d}-\mathrm{d}_{0} \\
& \text { Where: } \mathrm{E}(\mathrm{v})=\mathrm{A} \exp \left[-0.5 \mathrm{mv}^{2} / \mathrm{T}\right] \\
& \text { Analogously, for } \mathrm{E}_{3}=931 \mathrm{MeV} \text { : } \\
& \mathrm{T}_{3}=\mathbf{1 . 5 8} \mathrm{eV}=\mathbf{1 8 3 6 8 . 7 2} \text { kelvin }=\Delta \lambda \text { Gaussian }=\mathrm{d}-\mathrm{d}_{0} \\
& \text { Where: } \mathrm{E}(\mathrm{v})=\mathrm{A} \exp \left[-0.5 \mathrm{mv}^{2} / \mathrm{T}\right]
\end{aligned}
$$

For this Te ranges ( $1.55 \mathrm{eV}$ to $1.58 \mathrm{eV}$ ), the number density (ne) of thermal electrons can be calculated using the equation:

ne $=\Gamma /[\mathrm{kT} / 2 \Pi \mathrm{m}]^{1 / 2}$

Where:

$\Gamma=$ random flux of argon atoms at room temperature $\left[2 \times 10^{25}\right.$ atoms $\times \mathrm{m}^{-2} \times \mathrm{s}^{-1}$ ]

$$
\begin{aligned}
& \mathrm{K}=\text { Boltzmann }\left[8.617 \times 10^{-5} \mathrm{eV} \mathrm{m}^{2} \mathrm{~kg} / \mathrm{s}^{2} \mathrm{k}\right] \\
& \Pi=3.14 \\
& \mathrm{~m}=\text { argon mass }[\mathrm{kg}]
\end{aligned}
$$$$
\text { ne }=2 \times 10^{25} /\left[8.617 \times 10^{-5} \times 18150 / 2 \times 3.14 \times 6.4 \times 10^{-26}\right]
$$$$
\text { ne }=2 \times 10^{25} / 1.97 \times 10^{12}
$$$$
\text { ne }=1.012 \times 10^{13} \mathrm{~m}^{-3} \sim 10^{13} \mathrm{~m}^{-3}
$$

\section{Using the breakdown voltage $(\mathrm{Vb})$ for calculate Townsend coefficient of argon ionization}

Moreover, the Paschen law was used to calculate the breakdown voltage $(\mathrm{Vb})$. In this case, the equation can be found in ${ }^{107}$.

$\mathrm{Vb}=\mathrm{B} \mathrm{p} \mathrm{d} / \ln ($ Apd $)-\ln [\ln (1+1 / \gamma)]$

Where:

$$
\begin{aligned}
& \mathrm{P}=\text { argon pressure }=100 \mathrm{~Pa} \\
& \mathrm{~d}=\text { electrode distance }(\mathrm{m})=5.4 \times 10^{-3} \mathrm{~m} \\
& \mathrm{Vb}=260 \mathrm{~V} .
\end{aligned}
$$

$\gamma=$ Townsend coefficient of argon ionization, which represents the number of electrons produced by secondary processes, that explain the increase of ion current during the increase of the voltage, followed by relaxed electric field. (The higher efficiency of secondary ionization processes in argon discharge occurs in the region of the Paschen's minimum; in this case, next to $260 \mathrm{Vb}$ ).

$\mathrm{A}\left[\mathrm{Pa}^{-1} \mathrm{~cm}^{-1}\right] ; \mathrm{B}\left[\mathrm{V} \mathrm{Pa}^{-1} \mathrm{~cm}^{-1}\right]$ are constants, supposed to be: $1^{\circ}$ attempt: $\mathrm{A}=1.5$ for $\mathrm{B}=0.0984$

then, $\gamma=0.172$

$2^{\circ}$ attempt: $\mathrm{A}=4.14 \times 10^{-3}$ for $\mathrm{B}=1.57 \times 10^{-4}$

then, $\gamma=0.60$

$3^{\circ}$ attempt: $\mathrm{A}=0.09$ for $\mathrm{B}=1.35$

then, $\gamma=0.00386$

\section{CONCLUSIONS}

For experiment i, with the data collected from I-V curves, provided to the region of the linear fit, was not possible to estimate the real current saturation. A crude estimate of the electric field in a self-sustaining plasma can be obtained by supposing that electrons travel their entire free path in the direction of the field and lose all the gained energy in an optimum collision with the (cold) gas, (which suggests a scaling of temperature with $\mathrm{E} / \mathrm{p}$ ). This gives several volts/cm at 1 Torr in $\operatorname{argon}(133.32 \mathrm{~Pa})$. The relation $\mathrm{E} / \mathrm{p}$ is useful to calculate FWHM in order to estimate the temperature and number density of thermal electrons for argon mass of $6.4 \times 10^{-26} \mathrm{~kg}$.

In experiment ii, the number of secondary electrons production at the cathode induced by argon ions impact compensated the loss of electrons at the anode and there by enabled self-sustained discharge. To determine the breakdown threshold, the electric field distortion can be neglected, and the field can be assumed uniform and equal to the applied field. As with DC (and lowfrequency) breakdown, higher values of pd require larger voltages to achieve breakdown, and at low pd there is again a sharp rise in breakdown voltage. If the long path explanation is considered then, the penetration of the discharge into the gap between the electrode and the insulator allows the discharge length to vary as required and the breakdown voltage stays close to the minimum value of $260 \mathrm{~V}$.

In experiment iii, different velocities of the argon particles emission resulted in different Doppler shifts, the cumulative effect of which is the homogeneous line broadening. The following calculations are based on the assumption that the plasma between the two spherical electrodes is collisionless (this is reasonable because most of such electrostatic confinement fusion experiments are carried out at a pressure around $10^{-3}$ mbar where the mean free paths are in the order of the size of the machine). The temperature for different potentials was measured. For each applied potential, the wavelength resulted to the same peaks formation, around $420 \pm 0.5$ and $528 \pm 0.5 \mathrm{~nm}$. Moreover, for thermal plasmas with a gas temperature similar to the electron one, the mobility of ions is high and the impact approximation is also valid for ions, 
being their contribution to the broadening also Lorentzian. The spectrum of lines emission from argon plasmas resulted in 4 peaks ranged between 467 and $469 \mathrm{~nm}$ comprise ions excitation (electronic transitions). While the fusor is in progress, the spectra intensity (counts) will change, and then it is possible to determine the temperature $(\Delta \mathrm{T})$ in the plasma, changing from 7 to $10 \mathrm{eV}$. While argon ions are moving a Maxwell-Boltzmann distance $\left(\Delta \mathrm{d}=\mathrm{d}-\mathrm{d}_{0}\right)$, there are photon emission with initial velocity $\left(\mathrm{v}_{0}\right)$ to final velocity $\left(\mathrm{v}_{\mathrm{f}}\right)$ due to energy loss.

Analyzing the FWHM, it can be estimated for each temperature, $\Delta \mathrm{d}=\lambda_{2}-\lambda_{1} \approx 0.20 \pm 0.1 \mathrm{~nm}$. Using the equations $\mathrm{d} / \mathrm{d}_{0}=(1-\mathrm{v} / \mathrm{c})$, and $\Delta \mathrm{f}=\mathrm{v} / \mathrm{d}_{0}$, then, the estimated electrons frequency is 2.1363 $\mathrm{MHz}$. The distance $(\Delta \mathrm{d})$ does not change significantly for each condition, which means that the temperature does not change significantly as function of the applied $\Delta \mathrm{V}$.

For typical fusor energy $(\mathrm{MeV})$, the plasma temperature calculated ranged from 0.21 to $1.58 \mathrm{eV}$ while the number density was estimated as $1.012 \times 10^{13} \mathrm{~m}^{-3}$.

The number of electrons produced by secondary processes can be explained by Townsend coefficient $(\gamma)$ which explains the increase of ion current during the increase of the voltage, followed by relaxed electric field. The $\gamma$ depends on the constants $\mathrm{A}$ and $\mathrm{B}$ in the equation $\mathrm{Vb}=\mathrm{B} \mathrm{pd} / \ln (\mathrm{Apd})-\ln [\ln (1+1 / \gamma)]$, which assumes different values according to the plasma conditions.

\section{ACKNOWLEDGEMENTS}

The author would like to thank the European Fusion Education Network (FUSENET), the Eindhoven University of Technology (TU/e) by the magnificent opportunity and the Hotel $\mathrm{NH}$ Eindhoven Conference Centre Koningshof by the amazing accommodation.

\section{REFERENCES}

1. Langmuir I. Positive ion currents from the positive column of Mercury arcs. Science, 1923;58(1502):290-1. https://doi. org/10.1126/science.58.1502.290

2. Stenzel RL. (1997). FF. Chen, Plasma Physics and Controlled Fusion, 2 ed., Plenum Press, 1984.

3. Kato K, lizuka S. Analysis of Langmuir Probe Characteristics for Measurement of Plasma Parameters in RF Discharge Plasmas. J Appl Math Phys. 2016;4:1811-1836. https://doi.org/10.4236/ jamp.2016.49185

4. Rousseau A, Teboul E, Lang N, Hannemann M, Ropcke J. Langmuir probe diagnostic studies of pulsed hydrogen plasmas in planar microwave reactors. J Appl Phys. 2002;92(7):3463-71. https://doi.org/10.1063/1.1497454

5. Masherov PE. A cylindrical langmuir probe primary probe holder size effect on the results of local plasma diagnostics. Aerospace MAI J. 2016;23(2):42-9.
6. Masherov PE, Obukhov VA, Riaby VA, Savinov VP. International Symposium on Plasma Chemistry In 21st International Plasma Chemistry Society (IPCS). The Royal Australian Chemical Institute Incorporated [internet event] 2013 Aug 4-9; Cairns, Australia [cited year Month day]. Available at: https://www.raci. org.au/events/event/21st-international-symposium-on-plasmachemistry

7. Brockhaus A, Borchardt C, Engemann J. Langmuir probe measurements in commercial plasma plants. Plasma Sources Sci Technol. 1994;3(4):539-44. https://doi.org/10.1088/09630252/3/4/011

8. Pramila, Patel JJ, Rajpal R, Hansalia CJ, Anitha VP, Sathyanarayana $K$. Solving the Capacitive Effect in the High-frequency sweep for Langmuir Probe in SYMPLE. J Phys Conf Ser. 2017; 823(1):1-6. https://doi.org/10.1088/1742-6596/823/1/012019

9. Melzer A, Flohr R, Piel A. Comparison of probe measurements and emission spectroscopy in a radiofrequency discharge. Plasma Sources Sci Technol. 1995;4(3):424-31. https://doi. org/10.1088/0963-0252/4/3/012

10. MasherovPE, Piskunkov AF, Riaby VA, SavinovVP, Yakuninb VG. New Applications of Langmuir Probes. Phys At Nucl. 2017;80(11):1697700. https://doi.org/10.1134/S1063778817110114

11. Pieper JB, Goree J. Dispersion of Plasma Dust Acoustic Waves in the Strong-Coupling Regime. Phys Rev Lett. 1996;77(15):3137240. https://doi.org/10.1103/PhysRevLett.77.3137

12. Abe T, Oyama K-I. Langmuir Probe. In: Oyama K, Cheng CZ. An Introduction to Space Instrumentation. Tokyo, Japan: Terrapub 2013. https://doi.org/10.5047/aisi.010

13. Johnson EO, Malter L. A floating double probe method for measurements in gas discharges. Phys Rev.1950;80(1):58-68. https://doi.org/10.1103/PhysRev.80.58

14. Pilling LS, Bydder EL, Carnegle DA. A computerized Langmuir probe system. Rev Sci Instrum. 2006;74(7):3341-3346. https:// doi.org/10.1063/1.1581362

15. Bilik N, Anthony R, Merritt BA, Aydil ES, Kortshagen UR. Langmuir probe measurements of electron energy probability functions in dusty plasmas. J Phys D Appl Phys. 2015;48(10):1-105204 (9pp). https://doi.org/10.1088/0022-3727/48/10/105204

16. Lafleur T, Chabert P. Is collisionless heating in capacitively coupled plasmas really collisionless? Plasma Sources Sci Technol. 2015;24(4):1-10. https://doi.org/10.1088/0963-0252/24/4/044002

17. Lafleur T, Chabert P, Booth JP. Electron heating in capacitively coupled plasmas revisited. Plasma Sources Sci Technol. 2014:23(3):1-12. https://doi.org/10.1088/0963-0252/23/3/035010

18. Kechkar S. Experimental investigation of a low pressure capacitively-coupled discharge, Dublin. PhD Thesis [School of Physical Sciences] - Dublin City University; 2015.

19. Riaby VA, Masherov PE, Savinov VP, Yakunin VG. RF plasma probe diagnostics: a method for eliminating measurement errors for Langmuir probes with bare protective shields. J Phys Conf Ser. 2018;958:1-14. https://doi.org/10.1088/1742-6596/958/1/012006

20. Babu S. Investigation of structure observed in measured electron energy probability function in capacitively coupled oxygen discharge. NCPST 5th Radio Frequency Discharges Workshop; 2015 Jun 12; Dublin (Ireland)

21. Park C, Pamidi S, Graber L. Boltzmann Analysis of Cryogenic $\mathrm{He}-\mathrm{H} 2$ Gas Mixtures as Dielectric Media for High-Temperature Superconducting Power Devices. IEEE Trans Appl Supercond. 2017;27(4):1-6. https://doi.org/10.1109/TASC.2016.2637319 
22. Park C, Graber L, Pamidi S. The dielectric properties of gaseous cryogen mixtures of $\mathrm{He}, \mathrm{H} 2, \mathrm{Ne}$, and $\mathrm{N} 2$ in a temperature range of 50-80 K at pressures up to 2.0 MPa. J Appl Phys. 2017;21(8):113. https://doi.org/10.1063/1.4976565

23. Park C, Graber L, Cheetham P, Viquez JG, Kim CH, Pamidi S. A Versatile Modeling Technique for Predicting Dielectric Strength Improvements in Gas Mixtures for Superconducting Applications. IEEE Trans Dielectr Electr Insul. 2017;24(5):2755-64. https://doi. org/10.1109/tdei.2017.006653

24. Cheetham P, Kim W, Kim CH, Graber L, Rodrigo H, Pamidi S. Enhancement of Dielectric Strength of Cryogenic Gaseous Helium by Addition of Small Mol\% Hydrogen. IEEE Trans Appl Supercond. 2017;27(4):1-5. https://doi.org/10.1109/ TASC.2016.2642539

25. Korolov I, Donkó Z. Breakdown in hydrogen and deuterium gases in static and radio-frequency fields. Phys Plasmas. 2015;22(9):18. https://doi.org/10.1063/1.4929858

26. Demidov VI, Kudryavtsev AA, Kurlyandskaya IP, Stepanova OM. Nonlocal control of electron temperature in short direct current glow discharge plasma. Phys Plasmas. 2014;21(9):1-5. https:// doi.org/10.1063/1.4896717

27. Adams SF, Demidov VI, Bogdanov E, Koepke ME, Kudryavtsev AA, Kurlyandskaya IP. Suprathermal electron energy spectrum and nonlocally affected plasma-wall interaction in helium/ air micro-plasma at atmospheric pressure. Phys Plasmas. 2016;23(10):1-6. https://doi.org/10.1063/1.4964721

28. Lieberman MA, Lichtenberg AJ. Principles of Plasma, Discharges and Material Processing. 2 ed. Hoboken (NJ): Wiley; 2005.

29. Phelps AV, Petrovi ZL. Cold-cathode discharges and breakdown in argon: surface and gas phase production of secondary electrons. Plasma Sources Sci Tchnol. 1999;8(3):R21-R44. https://doi.org/10.1088/0963-0252/8/3/201

30. Demidov VI, Adams SF, Kaganovich ID, Koepke ME, Kurlyandskaya IP. Measurements of low-energy electron reflection at a plasma boundary. Phys Plasmas. 2015;22(10):1-5. https://doi.org/10.1063/1.4933002

31. Pai P, Azar MT. Sub 3-micron gap microplasma FET with 50 V turnon voltage. In Proceedings of the 2014 IEEE 27th International Conference on Micro Electro Mechanical Systems (MEMS); 2014 January 26-30; San Francisco (CA): IEEE; 2014. https://doi. org/10.1109/MEMSYS.2014.6765601

32. Loeb LB. Basic processes of Gaseous Electronics. Berkeley (CA): University of California Press; 1955.

33. Radjenović MR, Radjenović $B$. The role of the field emission effect in the deviations from the Paschen law. 28th ICPIG; 2007 Jul 1520; Prague, Czech Republic: ICPIG; 2007.

34. Mesyats GA. Ectons and their role in plasma processes. Plasma Phys Control Fusion. 2005;47(5A):A109.

35. Marić D, Hartmann P, Malović G, Donkó Z, Petrović ZL. Measurements and modelling of axial emission profiles in abnormal glow discharges in argon: heavy-particle processes. J Phys D Appl Phys. 2003;36(21):2639-48. https://doi. org/10.1088/0022-3727/36/21/007

36. Marić D, Škoro N, Maguire PD, Mahony CMO, Malović G, Petrović ZL. On the possibility of long path breakdown affecting the Paschen curves for microdischarge. Plasma Sources Sci Technol. 2012;21(3):1-6. https://doi.org/10.1088/0963-0252/21/3/035016

37. Phelps AV, Petrović ZL. Cold-cathode discharges and breakdown in argon: surface and gas phase production of secondary electrons. Plasma Sources Sci Technol. 1999;8(3):R21-R44. https://doi.org/10.1088/0963-0252/8/3/201
38. Petrović ZL, Phelps AV. Oscillations of low-current electrical discharges between parallel-plane electrodes. I. dc discharges. Phys Rev E. 1993;47:2806-15. https://doi.org/10.1103/ PhysRevE.47.2806

39. Marić D, Hartmann P, Malović G, Donkó Z, Petrović ZL. Measurements and modelling of axial emission profiles in abnormal glow discharges in argon: heavy-particle processes. J Phys D Appl Phys. 2003;35(21)

40. Paschen F. Ueber die zum Funkenübergang in Luft, Wasserstoff und Kohlensäure bei verschiedenen Drucken erforderliche Potentialdifferenz. Annalen Der Physik. 1889;273(5):69-75. https://doi.org/10.1002/andp.18892730505

41. Paschen F, Annalen der Physik, 1889;273(5):69-96.

42. Penning FM, Addink CCJ. The starting potential of the glow discharge in neon-argon mixtures between large parallel plates: I. Results. Physica. 1934;1(7-12):1007-27. https://doi.org/10.1016/ S0031-8914(34)80297-2

43. Miller HC. Breakdown potential of neon below the Paschen minimum. Physica, 1964;30(11):2059-67. https://doi. org/10.1016/0031-8914(64)90027-8

44. Auday G, Guillot PH, Galy J, Brunet H. Experimental study of the effective secondary emission coefficient for rare gases and copper electrodes. J Appl Phys. 1998;83(11):5917-21.

45. Lisovskiy VA, Yakovin SD, Yegorenkov VD. Low-pressure gas breakdown in uniform DC electric field. J Phys D Appl Phys. $\quad 2000 ; 33(21): 2722-30 . \quad$ https://doi.org/10.1088/0022 $3727 / 33 / 21 / 310$

46. Mariotti D, McLaughlin JA, Maguire P. Experimental study of breakdown voltage and effective secondary electron emission coefficient for a micro-plasma device. Plasma Sources Sci Technol. 2004;13(2):207-12. https://doi.org/10.1088/09630252/13/2/003

47. Charles C, Boswell RW, Takahashi K. Investigation of radiofrequency plasma sources for space travel. Plasma Phys Control Fusion. 2012;54(12):124021. https://doi. org/10.1088/0741-3335/54/12/124021

48. Liu W, Zhang D, Kong F. The Impact of Electrode Configuration on Characteristics of Vacuum Discharge Plasma. Plasma Sci Technol. 2012;14(2):122. https://doi.org/10.1088/10090630/14/2/08

49. Radmilović-Radjenović M, Matejčik Š, Klas M, Radjenović B The role of the field emission effect in direct-current argon discharges for the gaps ranging from 1 to $100 \mu \mathrm{m}$. J Phys $D$ Appl Phys. 2013;46(1):015302. https://doi.org/10.1088/0022 3727/46/1/015302

50. Mohammed SJ, Khalaf MK, Majeed MA, Jasem HE. Experimenta study on the effect of longitudinal magnetic field on Townsend discharge characteristics in low pressure argon gas. Int J Adv Appl Sci. 2017;4(2):91-95. https://do.org/10.21833/ ijaas.2017.02.016

51. Gainutdinov RKh, Mutygoullina AA, Khamadeev MA, Petrova AS. Unstable vacuum and spectrum of atoms with a superheavy nucleus. J Phys Conf Ser. 2013;478(1):012019. https://doi. org/10.1088/1742-6596/478/1/012019

52. Gainutdinov RKh, Mutygoullina AA, Petrova AS. Natura spectral-line broadening in atoms with unstable nuclei. J Phys Conf Ser. 2015;613(1):012003. https://doi.org/10.1088/1742$6596 / 613 / 1 / 012003$

53. Stenzel RL, Gruenwald J, Fonda B, Ionita C, Schrittwieser R Transit time instabilities in an inverted fireball. II. Mode jumping and nonlinearities. Phys Plasmas. 2011;18(1):012105. https://doi. org/10.1063/1.3533440 
54. Stenzel RL, Gruenwald J, Fonda B, Ionita C, Schrittwieser R. Transit time instabilities in an inverted fireball. I. Basic properties. Phys Plasmas. 2011;18(1):012104. https://doi.org/10.1063/1.3533437

55. Gruenwald J, Frohlich M. Coupling of transit time instabilities in electrostatic confinement fusion devices. Phys Plasmas. 2015;22:070701. https://doi.org/10.1063/1.4926820

56. Devia DM, Rodriguez-Restrepo LV, Restrepo-Parra E. Methods Employed in Optical Emission Spectroscopy Analysis: a Review. Ing Cienc. 2015;11(21):239-267. https://doi.org/10.17230/ ingciencia.11.21.12

57. Cadwell L, Huwel L. Time-resolved emission spectroscopy in lasergenerated argon plasmas-determination of Stark broadening parameters. J Quant Spectrosc Ra. 2004;83(34):579-98. https://doi.org/10.1016/S0022-4073(03)00106-7

58. Hutchinson $\mathbb{I H}$. Principles of Plasma Diagnostics. 2 ed. Cambridge (UK): Cambridge University Press; 2002. https://doi. org/10.1017/CBO9780511613630

59. Allen LH. Astrophysics: The Atmosphere of the Sun and Stars. 2 ed. New York (NY): Ronald Press; 1963.

60. Duguet $\mathrm{T}$, Fournée $\mathrm{V}$, Dubois J, Belmonte $\mathrm{T}$. Study by optical emission spectroscopy of a physical vapour deposition process for the synthesis of complex AlCuFe(B) coatings. Surf Coat Tech. 2010;205(1):9-14. https://doi.org/10.1016/j.surfcoat.2010.05.030

61. Qayyum A, Ikram M, Zakaullah M, Waheed A, Murtaza G, Ahmad R, Majeed A, Khattak NAD, Mansoor K, Chaudhary KA. Characterization of argon plasma by use of Optical Emission Spectroscopy and Langmuir Probe Measurements. Int J Mod Phys B. 2003;17(14):2749-59. https://doi.org/10.1142/ S0217979203018454

62. Bibinov NK. et al., Plasma Sources Sci Technol. 2005;14:109. Tuske O. et al., Rev. Sci. Instrum., 2004;75:1529.

63. Foissac C, Kristof J, Annusova A, Veis P, Supiot P. Spectroscopic diagnostics and modelling of a N2-Ar mixture discharge created by an RF helical coupling device: I. Kinetics of N2(B3Пg) and N2(C3Пu) states. PlasmaSources Sci Technol. 2012;21(5):055021. https://doi.org/10.1088/0963-0252/21/5/055021

64. Zhu X, Pu Y-K, Celik Y, Siepa S, Schungel E, Luggenholscher D, Czarnetzki U. Possibilities of determining non-Maxwellian EEDFs from the OES line-ratios in low-pressure capacitive and inductive plasmas containing argon and krypton. Plasma Sources Sci Technol. 2012;21(2):024003. https://doi.org/10.1088/09630252/21/2/024003

65. Tanışı M, Şahin N. Optical characteristics for capacitively and inductively radio frequency discharge and post-discharge of helium. Phys Plasmas. 2016;23(1):013513. https://doi. org/10.1063/1.4940783

66. Lock EH, Petrova TB, Petrov GM, Boris DR, Walton SG. Electron beam-generated Ar/N2 plasmas: The effect of nitrogen addition on the brightest argon emission lines. Phys Plasmas. 2016;23(4):043518. https://doi.org/10.1063/1.4946880

67. ZhuX, Y.-K. Pu, Y. Celik, S. Siepa, E. Schungel, D. Luggenholscher, and U. Czarnetzki, Plasma Sources Sci Technol. 2012;21:024003.

68. Zhu X, Pu Y. J Phys D Appl Phys. 2010;43:403001 Boffard JB, Jung RO, Lin CC, Wendt AE. Plasma Sources Sci Technol. 2010;19:065001.

69. [69] Bogaerts A, Gijbels R, Vlcek J. Modeling of glow discharge optical emission spectrometry: Calculation of the argon atomic optical emission spectrum. Spectrochim Acta Part B. 1998;53(11):1517-26. https://doi.org/10.1016/S05848547(98)00139-6
70. Bogaerts A, Gijbels R. Modeling of metastable argon atoms in a direct-current glow discharge. Phys Rev A. 1995;52(5):374351. https://doi.org/10.1103/PhysRevA.52.3743

71. Zhu X-M, Pu Y-K. Optical emission spectroscopy in lowtemperature plasmas containing argon and nitrogen: determination of the electron temperature and density by the line-ratio method. J Phys D Appl Phys 2010;43(40):403001-25. https://doi.org/10.1088/0022-3727/43/40/403001

72. Zhu X, Pu Y-K, Celik Y, Siepa S, Schungel E, Luggenholscher D, Czarnetzki U, Plasma Sources Sci Technol. 2012;21(2):024003. https://doi.org/10.1088/0963-0252/21/2/024003/meta

73. Zhu X, Pu Y-K. Optical emission spectroscopy in lowtemperature plasmas containing argon and nitrogen: determination of the electron temperature and density by the line-ratio method. J Phys D Appl Phys. 2010;43(40):403001.

74. Boffard JB, Jung RO, Lin CC, Wendt AE. Plasma Sources Science and Technology Optical emission measurements of electron energy distributions in low-pressure argon inductively coupled plasmas. Plasma Sources Sci Technol. 2010;19(6):065001. https://doi.org/10.1088/09630252/19/6/06500

75. Lock EH, Petrova TzB, Petrov GM, Boris DR, Walton SG. Electron beam-generated Ar/N2 plasmas: The effect of nitrogen addition on the brightest argon emission lines. Physics of Plasmas 2016;23:043518.

76. Dasgupta A, Blaha M, Giuliani JL, Electron-impact excitation from the ground and the metastable levels of $\mathrm{Ar}$ I. Phys Rev A. 1999;61(1):012703. https://doi.org/10.1103/ PhysRevA.61.012703

77. Allard N, Kielkopf $\mathrm{J}$. The effect of neutral non resonant collisions on atomic spectral lines. Rev Mod Phys. 1982;54:1103-82. https://doi.org/10.1103/RevModPhys.54.1103

78. Ali AW, Giem HR. Theory of resonance broadening of spectral lines by atom-atom impacts. Phys Rev. 1965;140(4A):10449. https://doi.org/10.1103/PhysRev.140.A1044. Erratum in: Phys Rev. 1966;144(1):366. https://doi.org/10.1103/ PhysRev.144.366

79. Ali AW, Giem HR. Theory of resonance broadening of spectral lines by atom-atom impacts. Phys Rev. 1965;140(4A):1044-9. https://doi.org/10.1103/PhysRev.140.A1044

80. Nikiforov AY, Leys C, Gonzalez MA, Walsh JL. Electron density measurement in atmospheric pressure plasma jets: Stark broadening of hydrogenated and non-hydrogenated lines. Plasma Sources Sci Technol. 2015;24(3):034001-18. https:// doi.org/10.1088/0963-0252/24/3/034001

81. Shafir G, Zolotukhin D, Godyak V, Shlapakovski A, Gleizer S, Slutsker Y, Gad R, Bernshtam V, Ralchenko Y, Krasik YE. Characterization of inductively coupled plasma generated by a quadruple antenna. Plasma Sources Sci Technol. 2017;26(2):025005, https://doi.org/10.1088/1361-6595/aa5300

82. Fox-Lyon N, Oehrlein GS, Godyak V. Effect of surface derived hydrocarbon impurities on Ar plasma properties. J Vac Sci Technol A. 2014;32(3):030601. https://doi. org/10.1116/1.4867158

83. Jogi I, Raud J, Hein K, Laan M. Spectral characterization of medium-pressure RF discharge in argon-oxygen mixture. J Phys D Appl Phys. 2014;47(33):335206. https://doi. org/10.1088/0022-3727/47/33/335206

84. K-I. Oyama, Y. W. Hsu, G. S. Jiang, W. H. Chen, C. Z. Cheng, H. K. Fang and W. T. Liu, Rev. Sci. Instrum. 86, 084703 (2015). D. Voloshina, A. Kovalev, Y. Mankelevich, O. Proshina, T. Rakhimova, and A. Vasilieva, Eur. Phys. J. D 69(1), 23 (2015). 
85. Tejero-del-Caz A, Palop JIF, Diaz-Cabrera JM, Ballesteros J Radial-to-orbital motion transition in cylindrical Langmuir probes studied with particle-in-cell simulations. Plasma Sources Sci Technol. 2016;25(1):01LT03. https://doi.orrg/10.1088/09630252/25/1/01LT03

86. Braithwaite NSJ. Introduction to gas discharges. Plasma Sources Sci Technol. 2000;9(4):517-27. https://doi.org/10.1088/09630252/9/4/307

87. Bustos A, Juarez AM, de Urquijo J, Muñoz M. An automated Langmuir probe controller for plasma characterization. Meas Sci Technol. 2016;27(8):087002. https://doi.org/10.1088/09570233/27/8/087002

88. Abe T, Oyama K. An Introduction to Space Instrumentation. Tokyo, Japan: Terrapub; 2013. 63-75 p.

89. Chung P, Talbot L, Touryan KJ. Electrical probes in stationary and flowing plasmas. New York (NY): Springer; 1975.

90. Braithwaite NSJ, Franklin RN. Reflections on electrical probes. Plasma Sources Sci Technol. 2009;18(1):014008. https://doi. org/10.1088/0963-0252/18/1/014008

91. Itagaki N, Iwata S, Muta K, Yonesu A, Kawakami S, Ishii N, Kawai Y. Electron-Temperature Dependence of Nitrogen Dissociation in 915 MHz ECR Plasma. Thin Solid Films 2003;435(1-2):259-63. https://doi.org/10.1016/S0040-6090(03)00395-X

92. Yong-ik S, Lim HB, Houk RS, Diagnostic Studies of Low-Pressure Inductively Coupled Plasma in Argon Using a Double Langmuir Probe. J Anal At Spectrom. 2002;17(6):565-9. https://doi. org/10.1039/b110219m

93. Radmilović-Radjenović M, Lee JK, Iza F, Park GY. Particle-in-cell simulation of gas breakdown in microgaps. J Phys D Appl Phys. 2005;38(6):950-4. https://doi.org/10.1088/0022-3727/38/6/027

94. Radmilović-Radjenović M, Radjenović B. The influence of ionenhanced field emission on the high-frequency breakdown in microgaps. Plasma Sources Sci Technol. 2007;16(2):337-40. https://doi.org/10.1088/0963-0252/16/2/017

95. Bekkara MF, Benmimoun Y, Tilmatine A, Miloudi K, Flazi S. An effective approach for designing a low pressure DC glow discharge plasma reactor. J Electrostat. 2017;88:225-31. https:// doi.org/10.1016/j.elstat.2017.01.004

96. Wais SI, Mohammed RY, Yousif SO. Influence of Axial Magnetic Field on the Electrical Breakdown and Secondary Electron Emission in Plane-Parallel Plasma Discharge. World Acad Sci Eng Technol. 2011;5(8):1226-31. https://doi.org/10.5281/ zenodo. 1333588

97. Raizer YP, Gas Discharge Physics. New York (NY): Springer; 1997

98. Petrović ZL, Škoro N, Marić D, Mahony CMO, Maguire PD, Radmilović-Radjenovic M, Malović G. Breakdown, scaling and volt-ampere characteristics of low current micro-discharges. $J$ Phys D Appl Phys 2008;41(19):194002. https://doi. org/10.1088/0022-3727/41/19/194002

99. Hutchinson IH. Principles of Plasma Diagnostics. 2 ed. New York (NY): Cambridge University Press; 2002. 264-265 p

100. Griem, HR. (1974) Spectral line broadening by plasmas. New York (NY): Academic Press; 1974.

101. Yubero C, Rodero A, Dimitrijevic M, Gamero A, García MC. Gas temperature determination in an argon non-thermal plasma at atmospheric pressure from broadenings of atomic emission lines. Spectrochim Acta Part B. 2017;129:14-20. https://doi. org/10.1016/j.sab.2017.01.002

102. Griem HR. Plasma spectroscopy. New York (NY): McGrow-Hill; 1964.

103. Griem HR. Spectral line broadening by plasmas. New York (NY) Academic Press; 1974.

104. Kunze HJ. Introduction to plasma spectroscopy. Berlin: Springer; 2009

105. Lieberman MA, Lichtenber AJ. Principles of Plasma Discharges and Materials Processing. 2005; (2), p. 128.

106. Hutchinson $I H$. Principles of Plasma Diagnostics. 2002; 2 ed. Cambridge University Press, New York.

107. Lieberman, Michael A.; Lichtenberg, Allan J. (2005). Principles of plasma discharges and materials processing (2nd ed.) Hoboken, N.J.: Wiley-Interscience. 